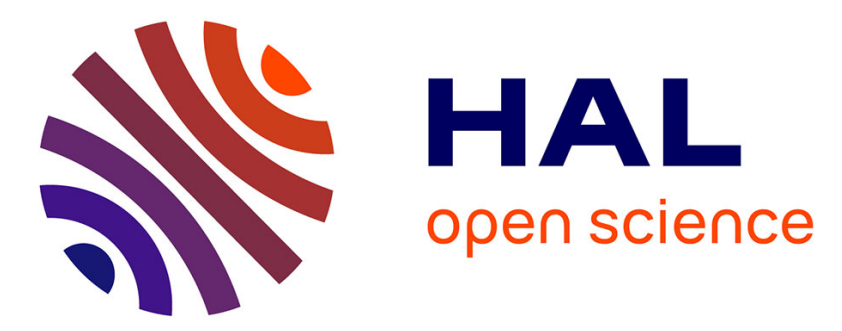

\title{
Mechanical Loss and Elastic Modulus Associated with Phase Transitions in PLZT Ceramics
}

\author{
B. Cheng, M. Gabbay, M. Gimenez, Gilbert Fantozzi
}

\section{To cite this version:}

B. Cheng, M. Gabbay, M. Gimenez, Gilbert Fantozzi. Mechanical Loss and Elastic Modulus Associated with Phase Transitions in PLZT Ceramics. Journal de Physique IV Proceedings, 1996, 06 (C8), pp.C8687-C8-690. 10.1051/jp4:19968149 . jpa-00254582

\section{HAL Id: jpa-00254582 https://hal.science/jpa-00254582}

Submitted on 1 Jan 1996

HAL is a multi-disciplinary open access archive for the deposit and dissemination of scientific research documents, whether they are published or not. The documents may come from teaching and research institutions in France or abroad, or from public or private research centers.
L'archive ouverte pluridisciplinaire HAL, est destinée au dépôt et à la diffusion de documents scientifiques de niveau recherche, publiés ou non, émanant des établissements d'enseignement et de recherche français ou étrangers, des laboratoires publics ou privés. 


\title{
Mechanical Loss and Elastic Modulus Associated with Phase Transitions in PLZT Ceramics
}

\author{
B.L. Cheng*, M. Gabbay, M. Gimenez** and G. Fantozzi \\ GEMPPM, UMR 5510 du CNRS, INSA Lyon, Bât. 502, 69621 Villeurbanne, France \\ * Department of Physics, South China University of Technology, Guangzhou 510641, China \\ ** Depto. Fisica de Los Materiales, UNED, Ciudad Universitaria, 28040 Madrid, Spain
}

\begin{abstract}
The phase transition in lanthanum modified lead zirconate-titanate ceramic of $6 / 60 / 40$ is studied by mechanical loss $\mathrm{Q}^{-1}$ and elastic modulus measurements. The shear elastic modulus measured from $50^{\circ} \mathrm{C}$ to $250^{\circ} \mathrm{C}$ shows that the Curie temperature is located at $180^{\circ} \mathrm{C}$ for the transition from cubic to thombohedral phase. The $Q^{-1}$ curves at low frequencies show clearly a peak corresponding to such phase transition. This phase transition is confirmed by measurements of Young's modulus and $\mathrm{Q}^{-1}$ using resonance curve technique from $-100^{\circ} \mathrm{C}$ to $300^{\circ} \mathrm{C}$ at kilohertz. Moreover, between $50^{\circ} \mathrm{C}$ and $90^{\circ} \mathrm{C}$, the resonance curve recorded at $\mathrm{kHz}$ frequency shows two resonance peaks. Such existence of double peaks means that a phase transition takes place between two rhombohedral phases FE2 and FE1 in the ferroelectric state. These phase transitions are also studied by DSC measurement.
\end{abstract}

\section{INTRODUCTION}

Lanthanum modified lead zirconate-titanate (PLZT) ceramic is used for application in electro-optic and has a potential use in non-volatile random access memory (RAM) devices since the discovery of transparent electro-optic ceramic by Haertling and Land [1]. Recently, Ramesh et al. reported that metaloxide electrodes yield better fatigue properties in PZT and PLZT than those with conventional Pt electrodes [2]. However, the apparent dielectric constant of PLZT was influenced by the electrode materials, and the domain switching was also influenced by the electrode materials at low temperature [3]. Concerning the application as holographic recording material, the holographic sensitivity is also controlled by both phase transition temperature and defect concentrations [4].

For obtaining a clear picture on the domain switching, and interaction of the ceramic with electrodes in PLZT, it could be helpful to get clear information on the phase transition and motion of domain walls in PLZT. It is known that PLZT ceramic is a ferroelectric-ferroelastic material [5]. Upon cooling down from cubic paraelectric phase to tetragonal or rhombohedral phase, the ferroelectric-ferroelastic PLZT ceramic is associated with shear strains that can be reoriented by applied stress. In this paper the mechanical loss and elastic modulus are studied on PLZT ceramic in order to find out dynamics of the phase transition in this donor doped ceramic.

\section{SPECIMENS AND EXPERIMENTAL PROCEDURES}

The PLZT studied is $\left(\mathrm{Pb}_{94} \mathrm{La}_{6}\right)\left(\mathrm{Zr}_{60} \mathrm{Ti}_{40}\right) \mathrm{O}_{3}$, noted as PLZT 6/60/40. The sample was pre-sintered for $1 \mathrm{~h}$ at $1150^{\circ} \mathrm{C}$ in oxygen, and sintered at $1240^{\circ} \mathrm{C}$ under pressure of $3 \mathrm{MPa}$ for $13 \mathrm{~h}$. Density of the ceramic was $7.70 \mathrm{~g} / \mathrm{cm}^{3}$ by dimension measurement. The average grain size is about $2.5 \mu \mathrm{m}$ by scanning electron microscope. The compacts were sliced into bars of $1.5 \times 5 \times 40 \mathrm{~mm}^{3}$ for mechanical loss and elastic modulus measurements. 
Differential scanning calorimetry (DSC) measurement was carried out by using Perkin-Elmer DSC7 system with heating rate of $10^{\circ} \mathrm{C} / \mathrm{min}$. The result was obtained after subtraction of the background.

$\mathrm{X}$-ray diffraction (XRD) measurements at room temperature were performed on a Rigaku diffractometer with graphite monochrometer [0002] by using $\mathrm{Cu} \mathrm{K \alpha}$ radiation. X-ray scans were carried out with a $2 \theta$ step of $0.02^{\circ}$ and $1.00 \% \mathrm{~min}$. The voltage of $\mathrm{x}$-ray tube was $40 \mathrm{kV}$, and the current was $25 \mathrm{~mA}$.

Mechanical loss and elastic modulus measurements were carried out by two methods. The shear elastic modulus $\mathrm{G}$ and $\mathrm{Q}^{-1}$ are measured from $50^{\circ} \mathrm{C}$ to $250^{\circ} \mathrm{C}$ by an inverted pendulum. Young's modulus $\mathrm{E}$ and $\mathrm{Q}^{-1}$ are measured at kilohertz range by using resonance curve method from $-100^{\circ} \mathrm{C}$ to $300^{\circ} \mathrm{C}$.

\section{RESULTS AND DISCUSSIONS}

Fig. 1 shows the phase diagram of PLZT ceramics $\left(\mathrm{Pb}_{100-\mathrm{X}} \mathrm{La}_{\mathrm{X}} \mathrm{Zr}_{65} \mathrm{Ti}_{35} \mathrm{O}_{3}\right)[6]$. In the diagram, $\mathrm{PE}$ is para-electric phase with cubic crystalline structure, FE's are ferroelectric phases, AFE is antiferroelectric phase. FE1 and FE2 have rhombohedral structures, and FE3 is considered as quasi-cubic phase.

For the concentration of $x=6$ at $\% \mathrm{La}$, there are three phase transitions during cooling:

1) from para to ferroelectric phases: PE to FE3, $190^{\circ} \mathrm{C}$; 2) from $\mathrm{FE} 3$ to $\mathrm{FE} 2$ in the ferroelectric state, $170^{\circ} \mathrm{C}$; 3) from $\mathrm{FE} 2$ to $\mathrm{FE} 1$ in the ferroelectric state, $60^{\circ} \mathrm{C}$.

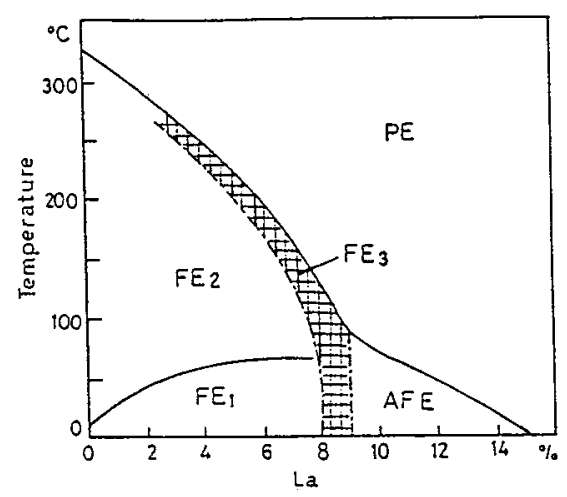

Figure 1: Phase diagram for PLZT (X/65/35) [6]

The phase structure of PLZT 6/60/40 cannot easily be determined, because the composition is close to the morphotropic phase boundary with the rhombohedral and tetragonal phase. By comparing the variations of dielectric constant before and after polarization, Paletto et al. pointed that the PLZT 6/60/40 has the rhombohedral phase [7]. However, from the XRD pattern of PLZT 6/60/40 in Fig. 2, the crystal structure of PLZT 6/60/40 could be indexed as a tetragonal phase. The parameters of unit cells are determined as $a=0.4080 \mathrm{~nm} ; c=0.4097 \mathrm{~nm}$. Considering the shape of the diffraction peaks of [002] and [200] and the values of $c / a=1.004$, the crystal structure of the material might be considered as quasi-rhombohedral as indicated in the Fig. 1.

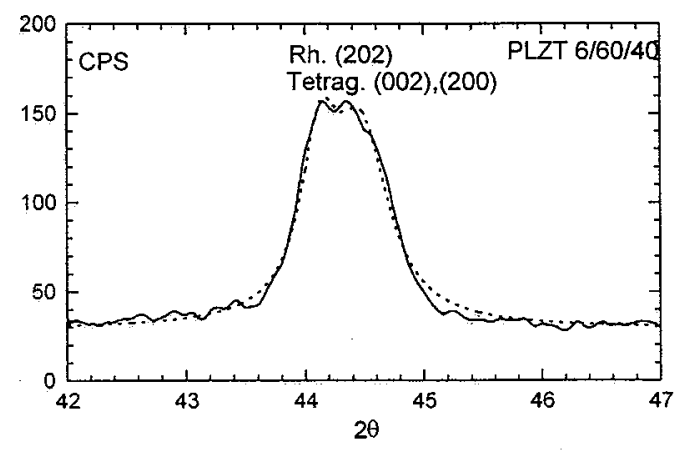

Figure 2: Room Temperature XDR from $42^{\circ}$ to $47^{\circ}$ of $2 \theta$

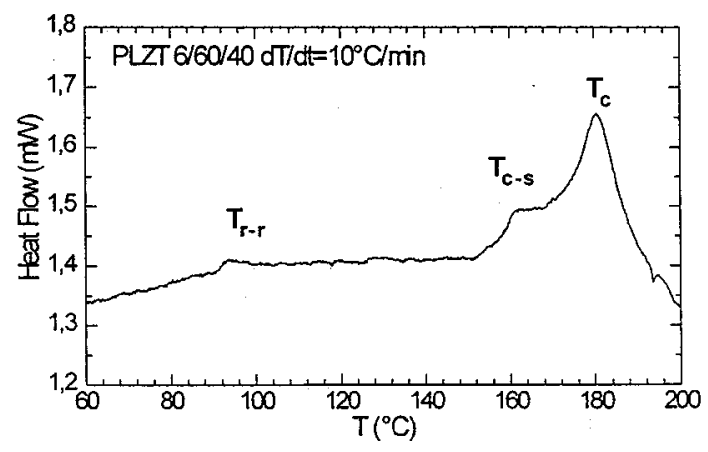

Figure 3: DSC measurement of PLZT 6/60/40

Fig. 3 gives the result of DSC measurement on PLZT ceramic. There are three peaks located at $180^{\circ} \mathrm{C}$ $\left(\mathrm{T}_{\mathrm{c}}\right), 160^{\circ} \mathrm{C}\left(\mathrm{T}_{\mathrm{c}-\mathrm{s}}\right)$, and $96^{\circ} \mathrm{C}\left(\mathrm{T}_{\mathrm{r}-\mathrm{r}}\right)$, respectively. It is possible to attribute the peak $\mathrm{T}_{\mathrm{C}}$ as the para- 
ferroelectric transition of PE-FE3, the peak $T_{c-s}$ as the transition of FE3-FE2, and $T_{r-r}$ as the transition of FE2-FE1 as it is shown in the phase diagram of the Fig. 1.

Fig. 4 shows the results of $Q^{-1}$ and shear modulus of PLZT $6 / 60 / 40$ ceramic during heating $\left(0.5^{\circ} \mathrm{C} / \mathrm{min}\right)$. There is one large loss peak located at $188^{\circ} \mathrm{C}$ and another small peak located at $95^{\circ} \mathrm{C}$. The heights of both peaks are reciprocally proportional to the vibration frequency. This is the feature of mechanical loss due to phase transition [8]. The peak located at $188^{\circ} \mathrm{C}$ corresponds to the ferro-paraelectric phase transition. This peak is connected to the anomaly of elastic modulus located at $180^{\circ} \mathrm{C}$. However, there is no minimum on the elastic mudulus at $95^{\circ} \mathrm{C}$. So other study is needed to clarify the origin of the $95^{\circ} \mathrm{C}$ peak.

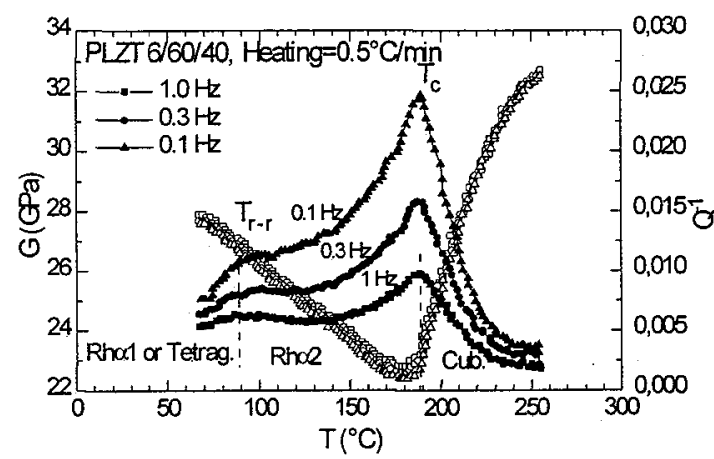

Figure 4: $G(T)$ and $Q^{-1}(T)$ at low frequencies

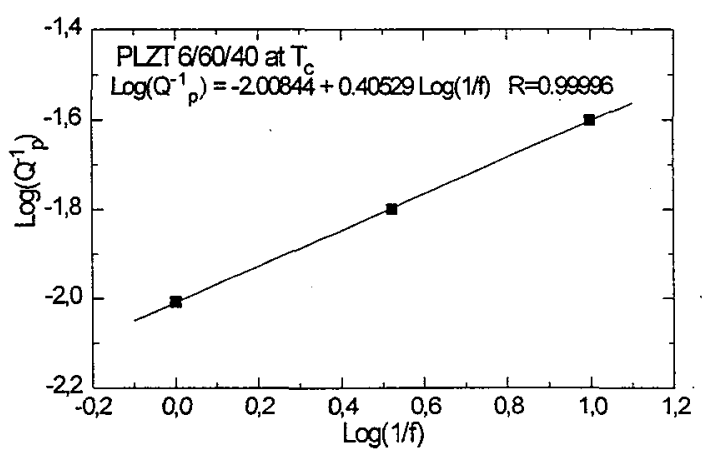

Figure 5: Exponent of phase transition at $T_{c}$

Concerning mechanical loss with phase transitions, it is accepted that the $\mathrm{Q}^{-1}$ associated with first order phase transition can be divided into three parts [9]:

1) $\mathrm{Q}^{-1} \mathrm{t}$, transient component occuring under non-isothermal conditions and at sufficiently low frequencies. It is determined by the thermally induced phase transformation rate.

2) $\mathrm{Q}^{-1} \mathrm{~s}$, stationary component occuring under either isothermal conditions or at frequencies at least in the kilohertz. It is related to the change in transformed fraction induced by the vibrating stress.

3) $\mathrm{Q}^{-1} \mathrm{i}$, attributed to the intrinsic damping generated in the two coexisting phases and can be written as $\mathrm{Q}^{-1} \mathrm{i}_{\mathrm{i}}=\kappa \mathrm{Q}^{-1}$ (new phase) $+(1-\kappa) \mathrm{Q}^{-1}$ (parent), where $\kappa=$ the fraction of the new phase.

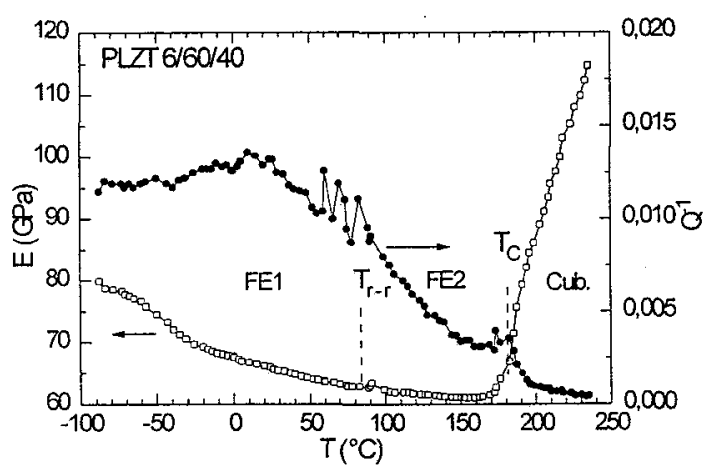

Figure 6: $E(T)$ and $Q^{-1}(T)$ at kilohertz

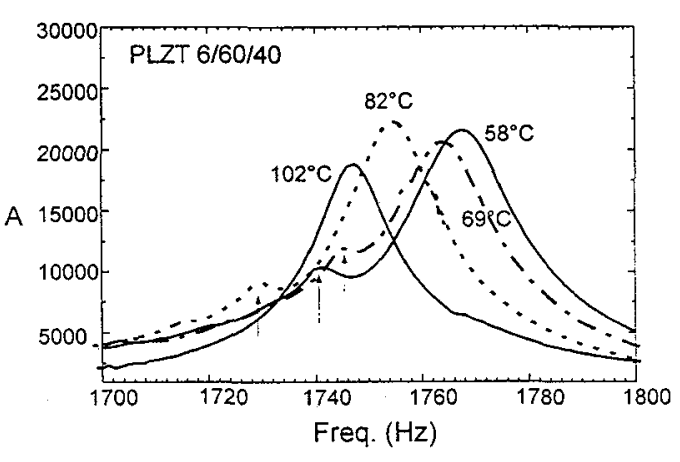

Figure 7: Double peaks on the resonance curves

Concerning the $Q^{-1}$ peak at low frequencies, it can be expressed as $Q^{-1}{ }_{t}=A(T)((d T / d t) / 2 \pi f)^{\alpha}$ with $0<\alpha<1$, where $d T / d t=$ the heating rate, $f=$ the frequency of the vibration [9]. Fig. 5 shows the dependence of $Q^{-1}$, on $1 / f$ of the material.The results show that the loss peak height changes with vibration frequency during the phase transition. Concerning such dependence of $Q^{-1}$, Wang et al. [10] consider that the nucleation rate of the new phase is in first approximation proportional to the stress, and the proportionality 
coefficient, $\mathrm{K}$, is controlled by the lattice softening near a first-order phase transition. They make a ad hoc hypothesis that $\mathrm{K}$ can be written as $\mathrm{K}=\beta /|\mathrm{Tc}-\mathrm{T}| \mathrm{n}$ with $0<\mathrm{n}<1$, and $\mathrm{n}=1-\alpha$. So that the exponent $\alpha$ is determined by the nucleation rate of the phase transition. The $\alpha$ is determined to be 0.4 .

Fig. 6 gives the results of $\mathrm{Q}^{-1}$ and Young's modulus $\mathrm{E}$ at kilohertz from $-100^{\circ} \mathrm{C}$ to $300^{\circ} \mathrm{C}$ on PLZT $6 / 60 / 40$. The $\mathrm{Q}^{-1}$ peak located at $185^{\circ} \mathrm{C}$ is linked with the Young's modulus anomaly which begins at $170^{\circ} \mathrm{C}$. Besides, we notice that between $50^{\circ} \mathrm{C}$ and $90^{\circ} \mathrm{C}$, the $\mathrm{Q}^{-1}$ values are scattered. Such scatterring is explained by the modification of resonance curves as it is shown in Fig. 7 . Along this temperature range $\left(50-90^{\circ} \mathrm{C}\right)$, we observe a second small resonance peak which height is temperature dependent. For temperatures higher than $100^{\circ} \mathrm{C}$, this second resonance peak disappears and the $\mathrm{Q}^{-1}$ values are no more scattered. So, it is reasonnable to suppose that in the $50^{\circ} \mathrm{C}-90^{\circ} \mathrm{C}$ temperature range, the two $\mathrm{FE} 1$ and $\mathrm{FE} 2$ rhombohedral phases coexist.Complementary experiments are needed in order to confirm such hypothesis and to verify if the ratio of resonnance peak heights is connected with the fraction of transformed phase.

\section{Conclusions}

In PLZT $6 / 60 / 40$ ceramic, the shear elastic modulus shows that the $T_{C}$ is located at $180^{\circ} \mathrm{C}$ for the transition from cubic to rhombohedral phase. The $Q^{-1}$ curves at low frequencies $(0.1 \mathrm{~Hz}$ to $1 \mathrm{~Hz})$ show clearly a peak of such phase transition. The height of this peak is frequency dependent. About the transition between the two rhombohedral FE1 and FE2 phases no elastic modulus anomaly and no $\mathrm{Q}^{-1}$ peak is observed. However, from $50^{\circ} \mathrm{C}$ and $90^{\circ} \mathrm{C}$ the resonance curves show two peaks and each of them could be attributed to one phase $\mathrm{FE} 1$ or FE2. Below $50^{\circ} \mathrm{C}$ the phase structure is only FE1 and above $90^{\circ} \mathrm{C}$ the transformation of the FE1 is finished. Such suggestion about this progressive phase transition needs complementary experiments.

\section{Acknowledgements}

The authors are very grateful to Dr. J. Paletto for providing the specimens and useful discussions.

\section{References}

[1] Haertling G.H. and Land C.E. , J.Ame. Ceram. Soc. 54 (1971),1-11.

[2] Ramesh R. , Inam A. , Chan W. K. , Tillerot F. , Wilkens B. , Chang C.C. , Sands T. , Tarascon J.M. , and Keramias V.G. , Appl. Phys. Lett. 59 (1991) 3542.

[3] Hsi C.S. , Haertling G.H. , and Furman E. , Appl. Phys. Lett. 64 (1994) 1050.

[4] Krumins A. and Sternberg A. , Third Euro-Ceramics, Vol. 2 Eds. by P. Duran and J.F. Fernandez, (Faenze Editrice Ibérice S.L. Sapin, 1993) pp.11-22.

[5] Wadhawan V.K., Kernion M.C., Kimura T., and Newnham R.P., Ferroelectrics, 37 (1981) 575-78.

[6] Sakaki Y., Yokosuka M., and Ochiai, Japanese J. of Applied Physics, 28 (1989) Supplement 28-2 pp.139-142

[7] Paletto J., private communication (1994)

[8] Postnikov V.S., Gridnev S.A., Darinskii B.M., and Sharshakov I.M., Il Nuovo Cimento, 33B (1976) 324-337.

[9] De Batist R., in: Mechanics and Mechanisms of Material Damping, Edited by V.K. Kinra and A. Wolfenden, (American Society for Testing and Materials ,Philadelphia, 1992) pp.45-59.

[10] Wang Ye-Ning, Chen Xiao-Hua, and Shen Hui-Min, Proc. of ICIFUAS-9, Edited by T.S. Kê, Beijing, China, July 1989, (International Academic Publisher, Beijing, Pergamon Press, Oxford, 1989) pp.305-312. 